\title{
Mecanismos de hidratação do óxido de magnésio
}

\section{(Mechanisms of magnesium oxide hydration)}

\author{
L. F. Amaral', R. Salomão ${ }^{1}$, E. Frollini ${ }^{2}$, V. C. Pandolfelli ${ }^{1}$ \\ ${ }^{1}$ Departamento de Engenharia de Materiais - DEMa, Universidade Federal de S. Carlos - UFSCar \\ Rod. Washington Luiz, km 235, S. Carlos, SP 13565-905 \\ ${ }^{2}$ Instituto de Química de S. Carlos - IQSC, USP \\ leaiqsc@yahoo.com.br, vicpando@power.ufscar.br
}

\begin{abstract}
Resumo
O óxido de magnésio, $\mathrm{MgO}$, é uma importante matéria-prima para a indústria de refratários por ser um material de elevada refratariedade (ponto de fusão próximo a $2800^{\circ} \mathrm{C}$ ), resistente a escórias básicas, e de custo competitivo. No entanto, em presença de água, o $\mathrm{MgO}$ rapidamente se hidrata formando hidróxido de magnésio, $\mathrm{Mg}(\mathrm{OH})_{2}$. Essa reação leva a uma expansão volumétrica de até três vezes, limitando sua aplicação em concretos refratários. Para desenvolver soluções que minimizem este problema, torna-se necessário um melhor entendimento do mecanismo pelo qual o $\mathrm{MgO}$ se hidrata e quais as principais variáveis envolvidas. Dois mecanismos distintos para esta reação foram propostos: a) dissolução seguida de precipitação e b) reação em uma única etapa ocorrendo diretamente na superfície das partículas. Este trabalho apresenta uma revisão crítica com relação aos mecanismos propostos e sua potencial aplicação em concretos refratários contendo $\mathrm{MgO}$. Suspensões aquosas de $\mathrm{MgO}$ e diferentes técnicas de caracterização (ensaios reológicos oscilatórios, medidas de expansão volumétrica aparente e condutividade iônica) permitiram correlacionar os mecanismos apresentados, principalmente com respeito à cinética da reação de hidratação.

Palavras-chave: óxido de magnésio, hidratação, concretos refratários.
\end{abstract}

\begin{abstract}
Magnesium oxide, $\mathrm{MgO}$, is an important raw material for refractories industry due to its high refractoriness (melting point of approximately $2800{ }^{\circ} \mathrm{C}$ ), corrosion resistance in basic environment and competitive cost. Nevertheless, $\mathrm{MgO}$ presents a great tendency to react with water producing magnesium hydroxide, $\mathrm{Mg}(\mathrm{OH})_{2}$. This reaction generates a threefold volumetric expansion and could lead to material breakdown inhibiting its application in refractory castables. In order to develop solutions to minimize this effect, a further understanding of the magnesia hydration mechanism and the main variables involved in this reaction is required. Two different mechanisms were proposed: a) dissolution followed by magnesium hydroxide precipitation and $b$ ) reaction in a single step that occurs on the particles surface. Aqueous suspensions were used in association with different characterization techniques (oscillatory tests, apparent volumetric expansion and ionic conductivity), showing relationships between the mechanisms presented mainly related to the kinetics of hydration of magnesia.
\end{abstract}

Keywords: magnesium oxide, hydration, refractory castables.

\section{INTRODUÇÃO}

Uma série de fatores econômicos ocorridos nas décadas de 70 e 80 , como a crise do petróleo e o desenvolvimento de materiais alternativos, induziu mudanças na indústria siderúrgica, para que esta pudesse se adaptar à nova realidade econômica. Desde então, o investimento em inovações tecnológicas tornou-se primordial para o desenvolvimento do setor, possibilitando a melhoria na qualidade do aço e o aumento da produtividade das siderúrgicas [1]. De modo análogo, a indústria de refratários sentiu-se pressionada a aprimorar sua tecnologia, já que fornece os insumos principais para o processo de obtenção do aço, influenciando diretamente seu custo final $[1,2]$. Um dos fatores que permitiram o avanço da indústria de refratários nesse período foi o desenvolvimento das técnicas de produção e instalação de refratários monolíticos, que apresentam maior versatilidade e menor custo comparados aos equivalentes pré-moldados convencionais [3, 4].

Nessa classe de materiais, os concretos refratários contendo óxido de magnésio ou magnésia $(\mathrm{MgO})$ destacamse devido a uma série de vantagens como sua elevada refratariedade e boa resistência ao ataque por escórias básicas. Em combinação com óxido de alumínio $\left(\mathrm{Al}_{2} \mathrm{O}_{3}\right)$, pode levar à formação de espinélio $\left(\mathrm{MgAl}_{2} \mathrm{O}_{4}\right)$, que possui boa resistência ao choque térmico, além de custo competitivo. As vantagens técnicas aliadas aos aspectos econômicos tornaram-se a motivação de muitos estudos na área de refratários.

Apesar de todas essas vantagens, o uso de $\mathrm{MgO}$ em concretos refratários tem se limitado devido aos problemas 
relacionados principalmente com a sua elevada tendência a se hidratar. Em presença de água (líquida ou vapor), o $\mathrm{MgO}$ rapidamente se hidrata formando hidróxido de magnésio, $\left(\mathrm{Mg}(\mathrm{OH})_{2}\right)$, também conhecido como brucita. Como os cristais de brucita (estrutura hexagonal e densidade 2,4 $\mathrm{g} / \mathrm{cm}^{3}$ ) apresentam menor densidade que a magnésia (estrutura cúbica e densidade $3,5 \mathrm{~g} / \mathrm{cm}^{3}$ ), durante a reação de hidratação, pode-se observar uma expansão volumétrica de até três vezes. Devido à grande eficiência de empacotamento dos concretos, essa expansão, em geral, tensiona a estrutura, podendo causar danos mecânicos como trincas, ou o efeito conhecido como "dusting", ou seja, a rápida desintegração do concreto, que podem ocorrer durante as etapas de cura e secagem [5-7]. Essas limitações restringem à utilização de magnésia na formulação de concretos a no máximo $10 \% \mathrm{em}$ peso e em granulometrias grosseiras (acima de $40 \mu \mathrm{m}$ ) [8].

Soluções que eliminem, reduzam ou contornem esses problemas podem levar ao desenvolvimento de concretos refratários com alto desempenho e durabilidade [9, 1]. Para isso, uma série de estudos foi realizada buscando uma melhor compreensão das peculiaridades do mecanismo, da cinética envolvida na reação de hidratação da magnésia e as principais variáveis envolvidas [10-15].

Dois mecanismos principais para a hidratação da magnésia podem ser encontrados. $\mathrm{O}$ primeiro, observado em temperaturas que variam entre $135^{\circ} \mathrm{C}$ e $200{ }^{\circ} \mathrm{C}(\mathrm{em}$ autoclave), é conhecido como "shrinking core model" e foi proposto com base em estudos que visam a utilização do $\mathrm{MgO}$ em materiais refratários [6]. Os autores sugerem que a hidratação da magnésia policristalina (forma mais comum de magnésia comercial empregada em refratários) ocorre em duas etapas que se diferenciam, principalmente, pela velocidade de reação. Inicialmente, ocorre a formação de uma camada de hidróxido de magnésio na área dos contornos de grão (mais reativas, já que possuem maior energia livre), gerando um tensionamento na estrutura e o conseqüente microtrincamento da partícula. Esse efeito leva à formação de partículas cada vez menores e à exposição de áreas ainda não reagidas. Dessa forma, a área e a velocidade de reação aumentam de forma exponencial até que restem apenas as unidades cristalinas mais estáveis, de menor reatividade e recobertas por uma camada de hidróxido de magnésio. A partir desse momento, a velocidade da reação começa a diminuir e passa a ser governada apenas pela difusão de água através da camada de hidróxido.

$\mathrm{O}$ segundo mecanismo, observado em menores temperaturas (abaixo de $90^{\circ} \mathrm{C}$ ) e baseado em um mecanismo de adsorção/precipitação [16] em estudos voltados ao melhor controle da reação de hidratação para a utilização do $\mathrm{Mg}(\mathrm{OH})_{2}$ como aditivo anti-chama em materiais poliméricos. Nesse trabalho, utilizando-se métodos e técnicas de caracterização mais sensíveis que aqueles utilizados anteriormente [6], foi observado que, em reações de hidratação conduzidas em temperaturas mais baixas (abaixo de $100{ }^{\circ} \mathrm{C}$ ), o "shrinking core model" não é o modelo mais adequado. Nessas condições, essa reação seria governada por um mecanismo composto de duas etapas. Inicialmente, ocorre a formação de íons $\mathrm{MgOH}^{+}$quimicamente adsorvidos na superfície das partículas de magnésia (equação A). Alguns estudos indicam que esse passo de adsorção é crítico para a hidratação da magnésia podendo controlar o processo de precipitação do hidróxido [17, 18]. Em seguida, ocorre a precipitação do hidróxido de magnésio (equação B):

$$
\begin{aligned}
& \mathrm{MgO}+\mathrm{H}_{2} \mathrm{O} \rightarrow \mathrm{MgOH}^{+}{ }_{\text {(superficie) }}+\mathrm{OH}^{-}{ }_{(\text {aq) }} \\
& \mathrm{MgOH}^{+}+\mathrm{OH}^{-} \rightarrow \mathrm{Mg}(\mathrm{OH})_{2(\mathrm{~s})}
\end{aligned}
$$

Quando se inicia a formação de $\mathrm{Mg}(\mathrm{OH})_{2}$, uma pequena porção do hidróxido se dissolve $\left(2,04 \times 10^{-4}\right.$ mol.L $\mathrm{L}^{-1}$, a $\left.25^{\circ} \mathrm{C}\right)$ segundo a reação

$$
\begin{aligned}
& \mathrm{Mg}(\mathrm{OH})_{2(\mathrm{~s})-} \mathrm{Mg}^{2+}(\mathrm{aq}) \\
& \mathrm{Kps}=\left[\mathrm{Mg}^{2+}\right]\left[\mathrm{OH}^{-}\right]^{2}=3,4 \times 10^{-11}
\end{aligned}
$$

Pelo fato da precipitação de hidróxido envolver íons hidroxila $\left(\mathrm{OH}^{-}\right)$, sua concentração é decisiva para a precipitação, existindo, portanto, uma faixa de $\mathrm{pH}$ (acima de 10) que delimita a formação do $\mathrm{Mg}(\mathrm{OH})_{2}$ [19]. Para valores de $\mathrm{pH}$ inferiores a 10 , os íons estão dissolvidos. Acima, estão precipitados. Outra consideração importante é que a solubilidade da brucita também pode ser reduzida com o aumento da temperatura [16].

\section{MATERIAIS E MÉTODOS}

Os testes foram realizados em suspensões $(67,7 \% \mathrm{p}$ de sólidos) de magnésia cáustica (Magnesita S.A.), preparadas com água deionizada previamente resfriada a $10{ }^{\circ} \mathrm{C}$, em um misturador de bancada (Ética Equipamentos Científicos S.A.), com rotação equivalente a $75 \%$ da potência máxima do equipamento, durante $2 \mathrm{~min}$.

Medidas de condutividade foram realizadas utilizando-se um condutivímetro Orion 3Star (ThermoElecton, Inglaterra), cuja faixa de medida varia entre $40 \mu \mathrm{S} / \mathrm{cm}$ e $200 \mathrm{mS} / \mathrm{cm}$ e um banho térmico (Fenix, ThermoElectron, Alemanha, erro $\pm 0,5{ }^{\circ} \mathrm{C}$ ), em temperaturas entre $10{ }^{\circ} \mathrm{C}$ e $80{ }^{\circ} \mathrm{C}$, com o objetivo de monitorar a concentração de espécies iônicas presentes na suspensão, em função do tempo de hidratação. Esses resultados serão apresentados na forma de curvas de condutividade versus tempo e também com os parâmetros $\mathrm{t}_{\mathrm{CM}}$ (tempo, em min, decorrido até a suspensão alcançar o máximo de condutividade), $\mathrm{C}_{\text {Máx }}$ (valor máximo atingido de condutividade em $\mathrm{mS}$ ) e $\mathrm{D}$ (taxa de decaimento da condutividade, após seu valor máximo em $\mathrm{mS} / \mathrm{min}$ ). Os valores de $\mathrm{D}$ foram calculados com a equação (E)

$$
D=\frac{C_{\max }-C_{f}}{t_{C M}-t_{f}}
$$

na qual $\mathrm{C}_{\mathrm{f}}$ e $\mathrm{t}_{\mathrm{f}}$ correspondem, respectivamente, ao valor de condutividade e ao tempo decorrido ao fim do teste.

Os ensaios oscilatórios são uma importante ferramenta 
empregada no estudo da consolidação de suspensões cerâmicas [20]. Nesses testes, a suspensão é submetida a tensões ou deformações oscilatórias (dependendo do modo de operação), aplicadas segundo uma função senoidal do tempo. Esse teste permite uma diferenciação entre as respostas viscosa e elástica do material. Elas podem ser expressas pelos módulos de armazenamento ou elástico (G') e de perda ou viscoso (G”). O primeiro indica o quanto da tensão aplicada pode ser temporariamente armazenada e instantaneamente recuperada e, fisicamente, representa o enrijecimento ou consolidação da suspensão. O segundo está associado à energia utilizada para iniciar o fluxo viscoso, irreversivelmente transformada em calor. Neste trabalho, o módulo G' foi o principal parâmetro utilizado.

Os ensaios oscilatórios foram realizados em reômetro rotativo(RS300, ThermoHaake, Alemanha) com a ferramenta tipo Vane e o módulo de controle de tensão. Inicialmente, determinaram-se os parâmetros de tensão $(1 \mathrm{~Pa})$ e freqüência (1 Hz) para que o teste de gelificação pudesse ser realizado dentro do limite viscoelástico linear. Em seguida,com essas condições, acompanhou-se a variação de $\mathrm{G}^{\prime}$ em função do tempo para diferentes temperaturas $\left(10-50{ }^{\circ} \mathrm{C}\right)$.

\section{RESULTADOS E DISCUSSÃO}

AFig. 1a mostra os resultados de medida de condutividade iônica em função do tempo das suspensões aquosas de magnésia, para diferentes temperaturas. Pode-se observar que, de acordo com o modelo de "adsorção/precipitação" [16], inicialmente ocorre um aumento da condutividade (em relação à condutividade da água pura), associado à adsorção química dos átomos de $\mathrm{H}^{+}$na superfície do óxido de magnésio e a conseqüente liberação de íons hidroxila na suspensão. Em seguida, a condutividade diminui, devido à precipitação do hidróxido e à conseqüente remoção de íons da solução. Apesar das limitações do equipamento utilizado não permitirem testes nas condições propostas em [6] (acima de $100{ }^{\circ} \mathrm{C}$ ), observa-se na Fig. $1 \mathrm{~b}$ uma clara tendência para o comportamento da condutividade com o aumento da temperatura (acima de $80^{\circ} \mathrm{C}$ ).

$\mathrm{Na}$ Fig. 2 o processo de adsorção dos íons $\mathrm{H}^{+}$na superfície das partículas de $\mathrm{MgO}$ é mostrado de forma esquemática, de uma perspectiva atômica. A Fig. 2a representa a célula unitária do óxido de magnésio. A Fig. $2 b$ mostra a adsorção acontecendo no plano das faces $\{100\}$ da célula unitária.

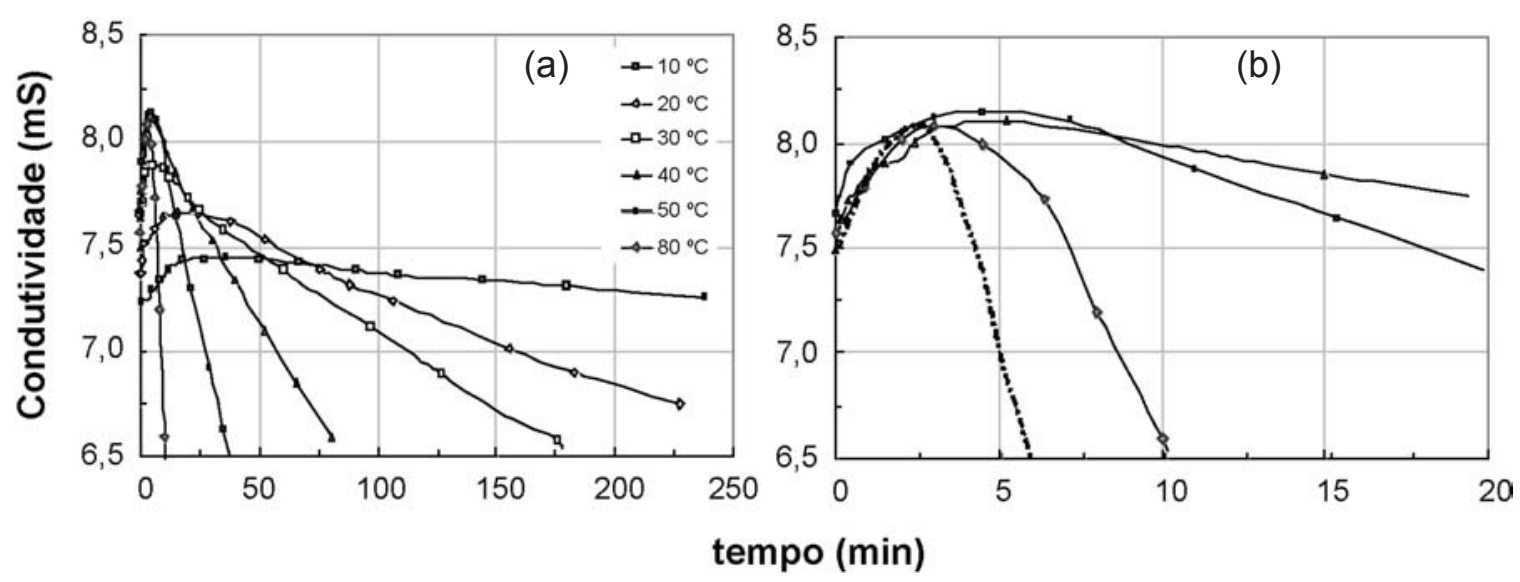

Figura 1: a) Condutividade iônica em função do tempo de suspensões aquosas de $\mathrm{MgO}$ para diferentes temperaturas, b) tendência da condutividade para temperaturas acima de $80^{\circ} \mathrm{C}$.

[Figure 1: a) Ionic conductivity as a function of the time for magnesia suspensions at different temperatures. $b$ ) Trend of ionic conductivity above $80^{\circ} \mathrm{C}$.]

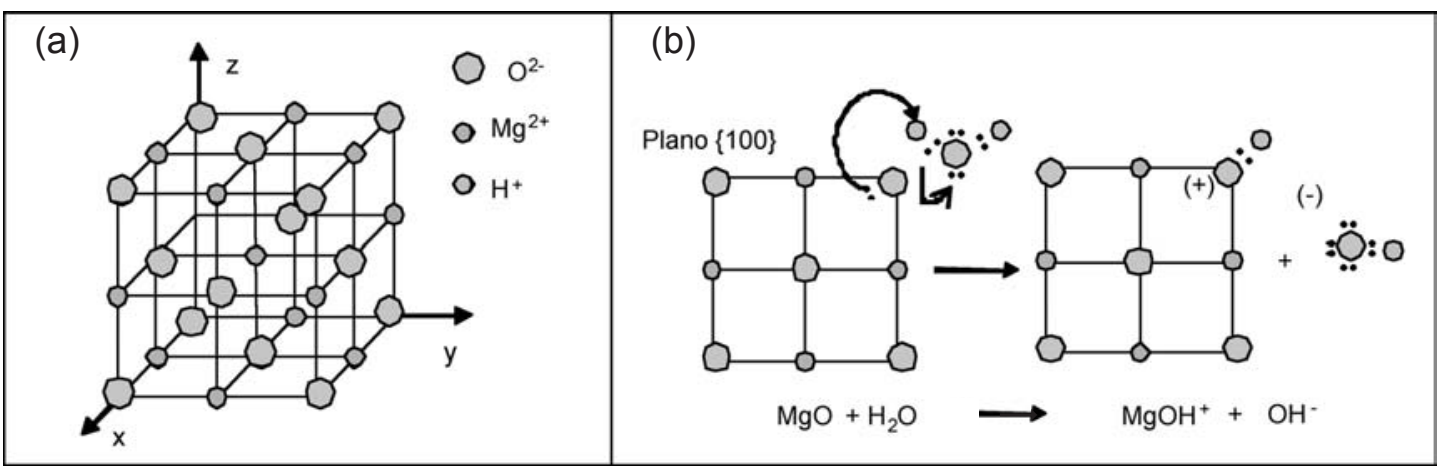

Figura 2: a) Célula unitária do óxido de magnésio, b) Mecanismo de adsorção dos íons $\mathrm{H}^{+}$na superfície do $\mathrm{MgO}$. [Figure 2: a) Unit-cell of magnesium oxide, b) Adsorption mechanism of protons on $\mathrm{MgO}$ surface.] 
Nessa figura, o oxigênio do óxido atua como base (doador de elétrons), enquanto o hidrogênio da água atua como ácido (receptor de elétrons), resultando na formação de $\mathrm{MgOH}^{+}$na superfície da partícula e $\mathrm{OH}^{-}$na suspensão. Como no processo de adsorção ocorre a formação de íons, há um aumento na condutividade iônica da suspensão. A partir desse momento, os ânions $\mathrm{OH}^{-}$reagem com os cátions $\mathrm{MgOH}^{+}$formando o hidróxido de magnésio.

Os resultados das medidas de condutividade iônica das suspensões de magnésia mostraram que tanto o estágio inicial de adsorção como o estágio final de precipitação (correspondentes ao aumento e a diminuição da condutividade, respectivamente) podem ser fortemente afetados pela temperatura (em temperaturas mais baixas, os dois processos ocorrem mais lentamente e vice-versa, Fig. 1). A partir da Fig. 1 três parâmetros foram analisados em termos do comportamento da condutividade em função da temperatura: a taxa de decaimento D, que fornece informações a respeito da velocidade de precipitação do hidróxido; o tempo decorrido até o ponto máximo da curva de condutividade, $\mathrm{t}_{\mathrm{CM}}$, que representa o tempo necessário para o início da precipitação; e o nível máximo de condutividade alcançado, $\mathrm{C}_{\mathrm{M}}$, relacionado a quantidade de íons adsorvidos na superfície da magnésia). A variação desses três parâmetros com a temperatura é mostrada na Fig. 3, onde as linhas contínuas correspondem às medidas experimentais e as descontínuas uma extrapolação para maiores temperaturas. Observa-se que o aumento da temperatura levou a um aumento na velocidade de precipitação (aumento de D) e á antecipação da precipitação (diminuição de $\mathrm{t}_{\mathrm{CM}}$ ). $\mathrm{O}$ nível de condutividade máxima $\left(\mathrm{C}_{\mathrm{M}}\right)$ se manteve aproximadamente fixo, indicando que nas maiores temperaturas (acima de $50{ }^{\circ} \mathrm{C}$ ) um mesmo nível máximo de adsorção foi atingido. A análise desses resultados sugere que o aumento da

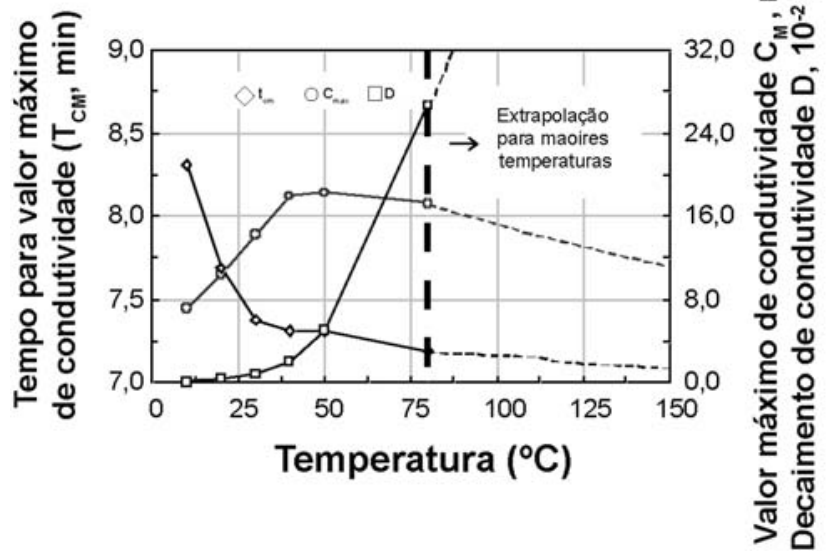

Figura 3. Tempo para início da precipitação, velocidade de precipitação e condutividade máxima em função da temperatura. [Figure 3: Time to start the brucite precipitation, precipitation rate and maximum conductivity versus temperature.] temperatura gerou uma maior força motriz para a precipitação dos compostos hidratados formados, mesmo quando já há uma estabilização da quantidade adsorvida. $\mathrm{O}$ aumento da temperatura acima de $100{ }^{\circ} \mathrm{C}$ é um agravante para a reação. Ela passa a ocorrer com água na fase de vapor, que além de possuir maior agitação molecular, dificulta a mobilidade iônica no meio (em relação à mobilidade dos íons na fase líquida). Dessa forma, em contato com o vapor aquecido, a adsorção ocorre quase instantaneamente levando a um aumento súbito de condutividade. Esses fatores contribuem para que o crescimento dos cristais ocorra de forma localizada, intensa e heterogênea, causando maior dano ao material. Além disso, deve-se considerar que a redução de solubilidade do hidróxido de magnésio com o aumento da temperatura [6] leva a um estado de supersaturação que rapidamente se desfaz em uma precipitação intensa.

A Fig. 4 mostra os resultados obtidos nos ensaios oscilatórios do módulo de armazenamento (G') em função do tempo para diferentes temperaturas. $\mathrm{O}$ aumento de G' representa o enrijecimento da suspensão. Esse enrijecimento pode estar relacionado à precipitação de $\mathrm{Mg}(\mathrm{OH})_{2}$ na superfície das partículas. A formação dessa camada diminui a mobilidade das partículas na suspensão e aumenta as interações entre elas. Como resultado, a suspensão começa a se tornar mais elástica em relação ao material inicial. Pode-se observar na Fig. 4 que o aumento da temperatura leva a uma redução dos intervalos de tempo necessários para o início do aumento de G'e ao aumento dos valores máximos atingidos. Esses resultados indicam que para um mesmo tempo de reação, há formação de maior quantidade de hidróxido para temperaturas mais elevadas e evidenciam a dependência da etapa de precipitação com a temperatura.

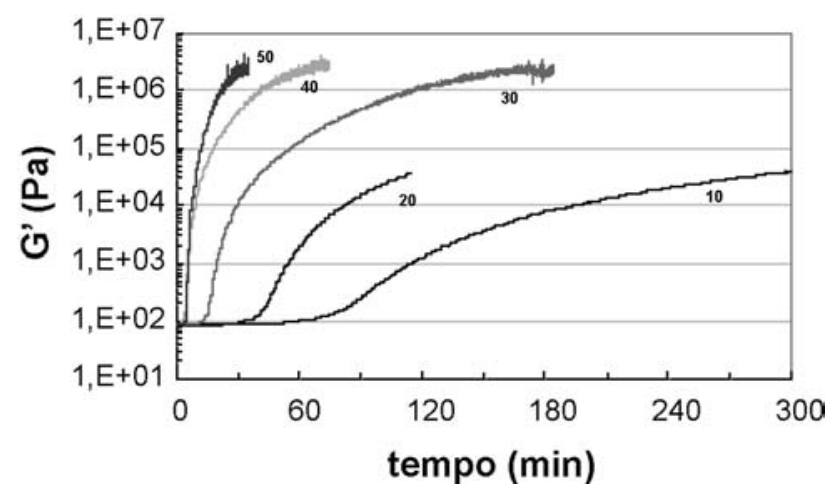

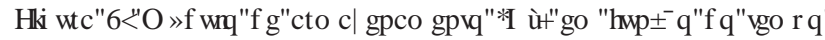
para diferentes temperaturas.

[Figure 4: Storage module $\left(G^{\prime}\right)$ versus time for different temperatures.]

A tendência da condutividade iônica em altas temperaturas mostrada nas Figs. 1b e 3 e os ensaios oscilatórios (Fig. 4) permitem que os dois mecanismos propostos para a reação de hidratação do $\mathrm{MgO}$ sejam correlacionados. A reação de hidratação sempre se inicia com o processo de adsorção/ 
precipitação, independentemente da faixa de temperatura. Em temperaturas mais baixas (menores que $50{ }^{\circ} \mathrm{C}$ ), ele é facilmente detectável e acompanhado por técnicas analíticas. Além disso, como ocorre mais lentamente, gera menos dano por expansão, já que o volume extra gerado tem mais tempo para se acomodar na estrutura do concreto. No entanto, em maiores temperaturas, as velocidades de adsorção/precipitação aumentam, dificultando a distinção de cada etapa individualmente, chegando ao extremo, em autoclave (acima de $80{ }^{\circ} \mathrm{C}$ ), onde parece que um único processo (precipitação) ocorreu. Neste caso, a maior velocidade de precipitação faz com que os danos por expansão sejam mais significativos [9].

\section{CONCLUSÕES}

Aspectos da reação de hidratação do $\mathrm{MgO}$ foram investigados utilizando diferentes técnicas de caracterização. Os resultados obtidos foram analisados baseando-se nos dois principais mecanismos descritos na literatura para essa reação. Os resultados de condutividade iônica indicaram que a hidratação da magnésia ocorre em duas etapas e que a extrapolação dos dados leva à união entre os dois mecanismos que se diferenciam principalmente na cinética e na possibilidade de detecção. Os ensaios oscilatórios sugerem que o início da precipitação leva a um maior contato entre as partículas que, com o passar do tempo, pode evoluir para o tensionamento da estrutura e seus problemas de expansão. $\mathrm{O}$ mecanismo unificado permite propor algumas possibilidades em termos de evitar os problemas causados pela hidratação da magnésia: a) evitar o processo de adsorção da água na superfície da partícula; b) evitar a precipitação do $\mathrm{Mg}(\mathrm{OH})_{2}$; c) acomodar os produtos formados, seja por menores velocidades de reação, menores quantidade de produto formado ou, ainda, maior espaço para sua acomodação na microestrutura.

\section{AGRADECIMENTOS}

Os autores agradecem à FAPESP e à Magnesita S. A. pelo apoio dado na realização desta pesquisa.

\section{REFERÊNCIAS}

[1] C. M. Peret, J. A. Gregolin, L. I. Faria, V. C. Pandolfelli, Refractories Applic. News 12, 1 (2007) 10.

[2] Z. Ningsheng, H. Shuhe, Z. Sanhua, China's Refractories 13, 2 (2004) 3.

[3] R. Salomão, L. R. M. Bittencourt, V. C. Pandolfelli, Cerâmica 52 (2006) 146.

[4] W. E. Lee, W. Vieira, S. Zhang, K. Ghanbari, H. Sarpoolaky, C. Parc, Int. Mater. Rev. 46, 3 (2001) 145.

[5] G. K. Layden, G. W. Brindley, J. Am. Ceram. Soc. 46, 11 (1963) 518.

[6] K. Kitamura, K. Onizukak, K. Tanaka, Taikabutsu Overseas 16, 3 (1995) 3.

[7] A. Kaneyasu, S. Yamamoto, A. Yoshida, Taikabutsu Overseas 17, 2 (1996) 21.

[8] A. Nishikawa, Tokyo: Technical Report 33, 7 (1984) 98.

[9] R. Salomão, L. R. M Bittencourt, V. C Pandolfelli, Ceram. Int. 33, 5 (2007) 803.

[10] V. S. Birchal, S. D. F. Rocha, M. B. Mansur, V. S. T. Ciminelli, Can. J. Chem. Eng. 79, 4 (2001) 507.

[11] K. R. Janowski, R. C. Rossi, J. Am. Ceram. Soc. 51, 8 (1968) 453.

[12] R. A. Wogelius, K. Refson, D. G. Fraser, G. W. Grime, J. P. Goff, Geochim. Cosmochim. Acta 59, 9 (1995) 1875.

[13] V. S. S. Birchal, S. D. F. Rocha,V. S. T. Ciminelli, Minerals Eng. 13, (2000) 1629.

[14] P. J. Anderson, R. F. Horlock, J. F. Oliver, Trans. Faraday Soc. 61, 516 (1965) 2754.

[15] P. R. G. Brandão, G. E. Gonçalves, A. G. Morato, Refractories Applic. News 8, 6 (2003) 23.

[16] S. D. Rocha, B. M. Mansur, V. S. T. Ciminelli, J. Chem. Techn. Biotechn. 79, 8 (2004) 816.

[17] D. Fillipou, N. Katiforis, N. Papassiopi, K. Adam, J. Chem. Techn. Biotechn. 74, 4 (1999) 322.

[18] O. Fruhwirth, G. W. Herzog, L. Hollerer, A. Rachetti, Surface Techn. 24, 3 (1985) 301.

[19] A. Vogel, Química Analítica Qualitativa, Ed. Mestre Jou, S. Paulo (1981) 93-100.

[20] R. D. dos Anjos, M. Ismael, R. Salomão, V. C. Pandolfelli, Refract. Applic. News 11, 2 (2006) 8.

(Rec. 02/03/2007, Rev. 18/04/2007, Ac. 27/04/2007) 